\title{
NOTE
}

\section{Radon exhalation from the Upper Silesian coal ashes}

\author{
A. T. SOLECKI* and D. E. TCHORZ-TRZECIAKIEWICZ \\ Institute of Geological Sciences, University of Wroclaw, pl. M. Borna 9, Wroclaw 50-204, Poland
}

(Received April 30, 2008; Accepted February 9, 2009)

\begin{abstract}
The radon exhalation has been measured for samples of coal ashes by the can technique. In this technique, the ratio of the radon content in the air inside the can and the total radium content of the sample is often regarded to be the approximation of the emanation coefficient. In fact it is the exhalation coefficient, measure of the exhalation from the sample, and depends strongly on the sample size and geometry. Analysis of the relation between the defined exhalation coefficient and the sample thickness resulted in the exponential function. The exponential function for thickness approaching zero results in exhalation coefficient equal $13 \%$, which can be treated as an approximation of emanation coefficient.
\end{abstract}

Keywords: radon exhalation, coal ashes, emanation coefficient, exhalation coefficient, Poland

\section{INTRODUCTION}

Emission of radioactive nuclides, which is considered as a potential risk, is mainly controlled by the local geology and structures (e.g., Durrance, 1986; Cothern and Smith, 1987; Baixeras et al., 2001; Sharma et al., 2003; Yang et al., 2003, 2011; Kies et al., 2011; Mehra et al., 2011; Tchorz-Trzeciakiewicz and Solecki, 2011; Vaupotič et al., 2011; Wysocka, 2011). Risk of radon exhalation from coal ashes is a significant problem, if one takes into account the fact, that in spite of decrease in European coal mining, the lignite is still significant and perspective fuel in many countries. In the case of Poland the problem of ash storage and brown fields rehabilitation emerges due to the millions tons of production and hundreds years of potential exploitation. Uranium content of coal is, in the most cases, below 1 ppm. However, in Polish deposits, locally, uranium mineralization results in values as high as 1000 ppm (Bareja et al., 1987). Therefore, uranium and thorium content and radon migrating from coal ashes are important from the ecological point of view.

Process of radon migration usually can be described by two quantities:

Radon emanation coefficient (\%) describes the fraction of Rn atoms which are able to escape the solid phase of the rock (soil) and enter the air (or fluids) in the open pores. It is calculated by dividing the amount of radon released into pores by the total number of radon "born" due to radium decay in the ground (sample).

*Corresponding author (e-mail: andrzej.solecki@ing.uni.wroc.pl)

Copyright $@ 2011$ by The Geochemical Society of Japan.
Radon flux $\left(\mathrm{Bq} \mathrm{m}^{-2} \mathrm{~s}^{-1}\right)$ is the physical quantity describing radon release across unit surface of the ground (IAEA, 1992). Sometimes, the term exhalation rate (Bq $\mathrm{m}^{-2} \mathrm{~h}^{-1}$ ) is used (Singh et al., 1999; Tufail et al., 2000; Sharma et al., 2003) in the case of laboratory measurements of soil (rock) samples. Radium content and amount of radon atoms originating inside the ground (or sample) is not taken into account by evaluating radon flux.

However, if the amount of radon released from the sample is divided by total amount of radon "born" inside the sample (or total amount of decayed radium) obtained result commonly referred to as emanation coefficient (or effective radium content) should be termed as exhalation coefficient. In such case, not only the radium content, but the surface to volume ratio of the sample is extremely important.

Various approaches have been applied to study radon release from ground and samples. The first and most popular attempt is to measure radon concentration in soil gas, what requires either sniffing equipment or making a hole in the ground to place various radon detectors inside (Durrance, 1986; Chyi et al., 2005, 2011; Yang et al., 2005; Fu et al., 2008, 2009; Walia et al., 2008, 2009). The second way is to measure radon exhalation (flux) from the ground (or sample) by placing a cup with the detector on the ground (or sample) surface (IAEA, 1992; AlJarallaha et al., 2001; Fazal-ur-Rehmana et al., 2003). The third approach is the laboratory one, where samples are put inside sealed container and radon concentration of trapped air is measured (Azam et al., 1995; Jönson, 1999; Baixeras et al., 2001; Oufni, 2003; Kumar et al., 2005; Mahur et al., 2008; Chyi et al., 2010). To make the 
results comparable, strict procedures with precisely defined dimensions of samples and containers are required.

In the case of the can technique the total radon content in the air (proportional to radon flux) inside the can is measured and divided by the total radium content of the sample. It is in fact the measure of the exhalation (not emanation) coefficient. It depends also on the sample thickness, since the radon atoms must leave not only minerals but the whole sample, where diffusion through coal ash layer is a dominant problem (Chauhan and Chakarvarti, 2002).

Radon release from solid bodies of various geometry is the main factor determining radon atmospheric activity over mine tailings, waste disposals and last, but not least, inside dwellings. Neither radon emanation coefficient, nor radon flux or exhalation rate can describe whole complexity of the problem. Radon emanation refers only to the internal process of the solid body, not taking into account the amount of radon released from it. In the case of radon flux or exhalation, the internal free radon content of the body is not taken into account. Thin layers of rock, soil or waste material does not attract human attention, in spite of the fact, that the majority of radon flux is generated by them and not by the huge interior of tailings, where radon is trapped inside.

In this study, the fine grained ash, remain of the Upper Silesian Carboniferous coal burning with ${ }^{226} \mathrm{Ra}$ content of $56 \mathrm{~Bq} \mathrm{~kg}^{-1}$ was used to study the influence of the sample thickness upon the exhalation process.

\section{METHOD}

Measurements of radium content have been performed in the landfill of coals ashes using portable Exploranium GR-320 gamma radiation spectrometer with the standard $\mathrm{NaI}$ (Tl) GPX-21A detector of $0.35 \mathrm{~L}$ volume. The producer using traceable test pads performed calibration of the detector. For each measurement the detector was deployed in the field using geometry as close as possible to $2 \Pi$. Sampling time ranged from 15 to 30 minutes depending on local radionuclides content to reach statistically significant counts. Ambient temperature during measurements was in the range 5 to $25^{\circ} \mathrm{C}$.

According to producers manual impulses supplied by the detector probe were classified using channels 70-204 of the 256 channels of the spectrometer covering the energy window $850-2810 \mathrm{keV}$. Measured activities of ${ }^{214} \mathrm{Bi}$ (1760 keV peak) and ${ }^{208} \mathrm{Tl}(2620 \mathrm{keV}$ peak) were automatically recalculated into uranium and thorium concentrations (in ppm) assuming existence of equilibrium in uranium and thorium decay series, what is a common practice in this kind of measurements marked by eU and eTh notation instead of $U$ and $T h$. For further calculations the activity of ${ }^{226} \mathrm{Ra}$ was assumed to be equal to the mea-

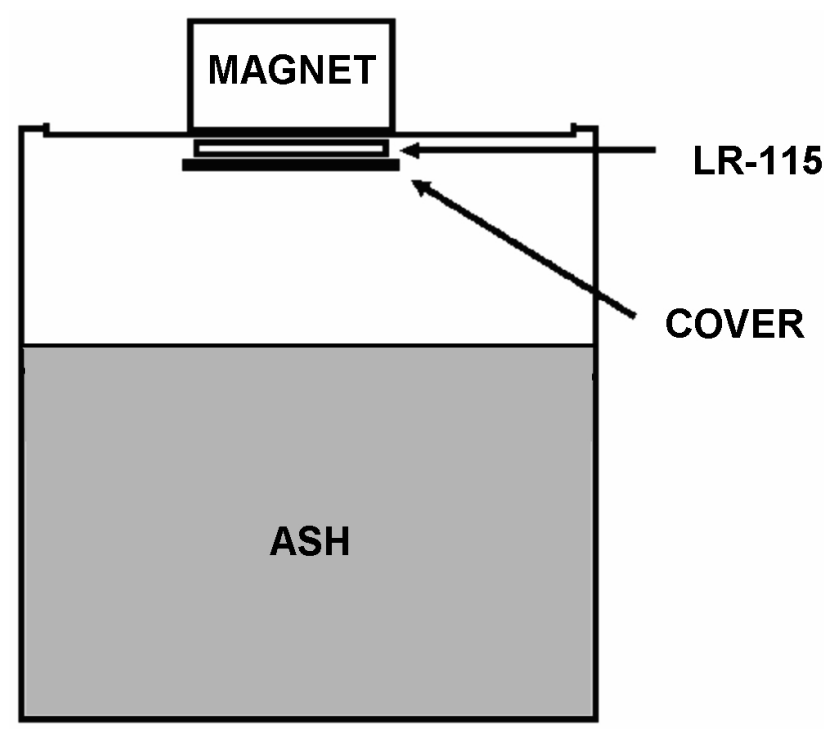

Fig. 1. Exhalation Can arrangement in this study.

sured ${ }^{214} \mathrm{Bi}$ activity.

In the place of measurements, ash sample was taken from the area of $1 \mathrm{~m}^{2}$ to the depth of $0.1 \mathrm{~m}$. After wellmixing, representative sample of $5 \mathrm{~kg}$ was taken for further laboratory analysis. Radon exhalation was measured using can technique described by Azam et al. (1995) and modified by Solecki (1999) (Fig. 1). Eight homogenized and sieved samples of ashes with ${ }^{226} \mathrm{Ra}$ activity of $56 \mathrm{~Bq}$ $\mathrm{kg}^{-1}$ were placed in iron cans with $0.2 \mathrm{~m}$ high of $5 \mathrm{dm}^{3}$ volume, to form layers of various thicknesses $(0.01,0.026$, $0.050,0.064,0.084,0.103,0.126$ and $0.158 \mathrm{~m}$ ) on the bottom of cans.

Passive open type track detectors Kodak LR115 were fixed at the top of cans and cans sealed. After 21 days iron cover held by the magnet was removed and detector exposed for 21 days in temperature of $20^{\circ} \mathrm{C}$. This procedure significantly simplifies calculation procedures since radon concentration equilibrium is achieved before exposition of track detector.

After exposition detectors were etched 90 minutes in $2.5 \mathrm{M} \mathrm{NaOH}$. Tracks were counted using optical microscope at the magnification of $100 \times$. And then, obtained track density can be recalculated into radon concentration.

Total radon concentration in the air inside the can was divided by the total radium activity of the sample, resulting in exhalation coefficient which for very thin samples can be regarded as the approximation of the emanation coefficient. Mineral composition of the ash has been studied by XRD method. Packing density, specific density and porosity of samples were measured by water flooding method. 


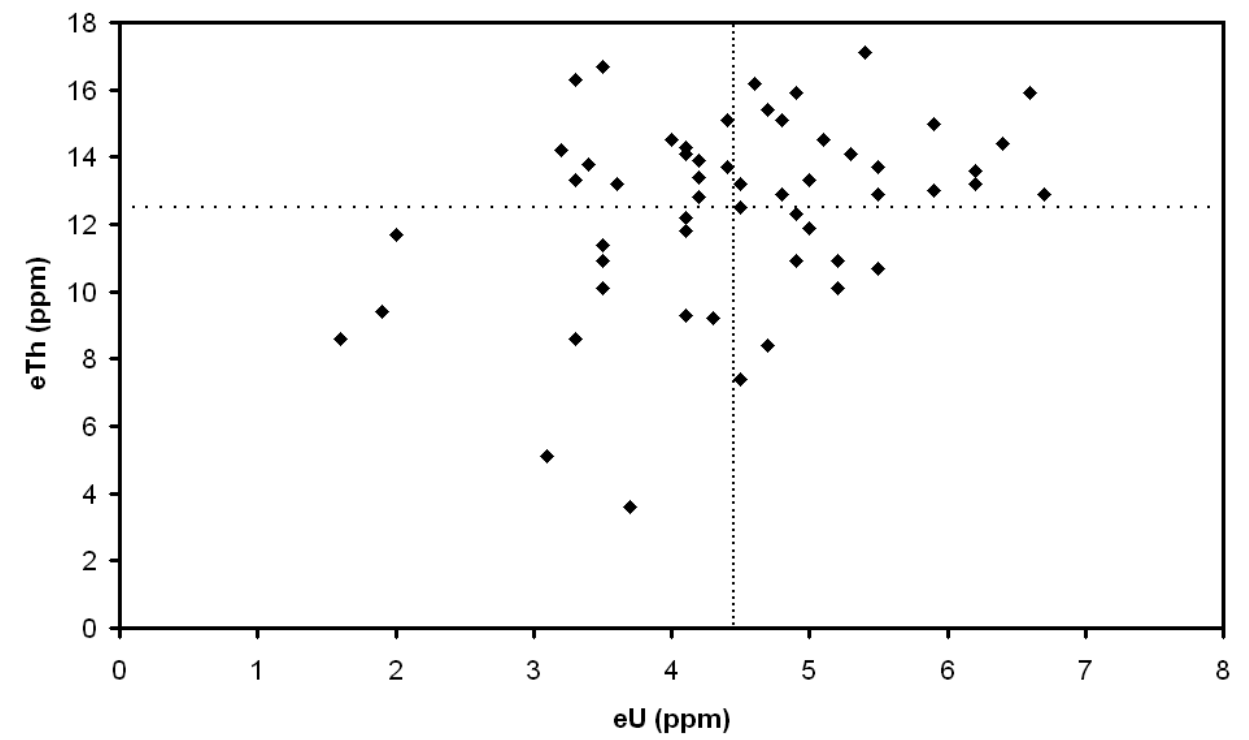

Fig. 2. Results of uranium (eU) and thorium (eTh) in situ measurements, mean values marked by dotted lines.

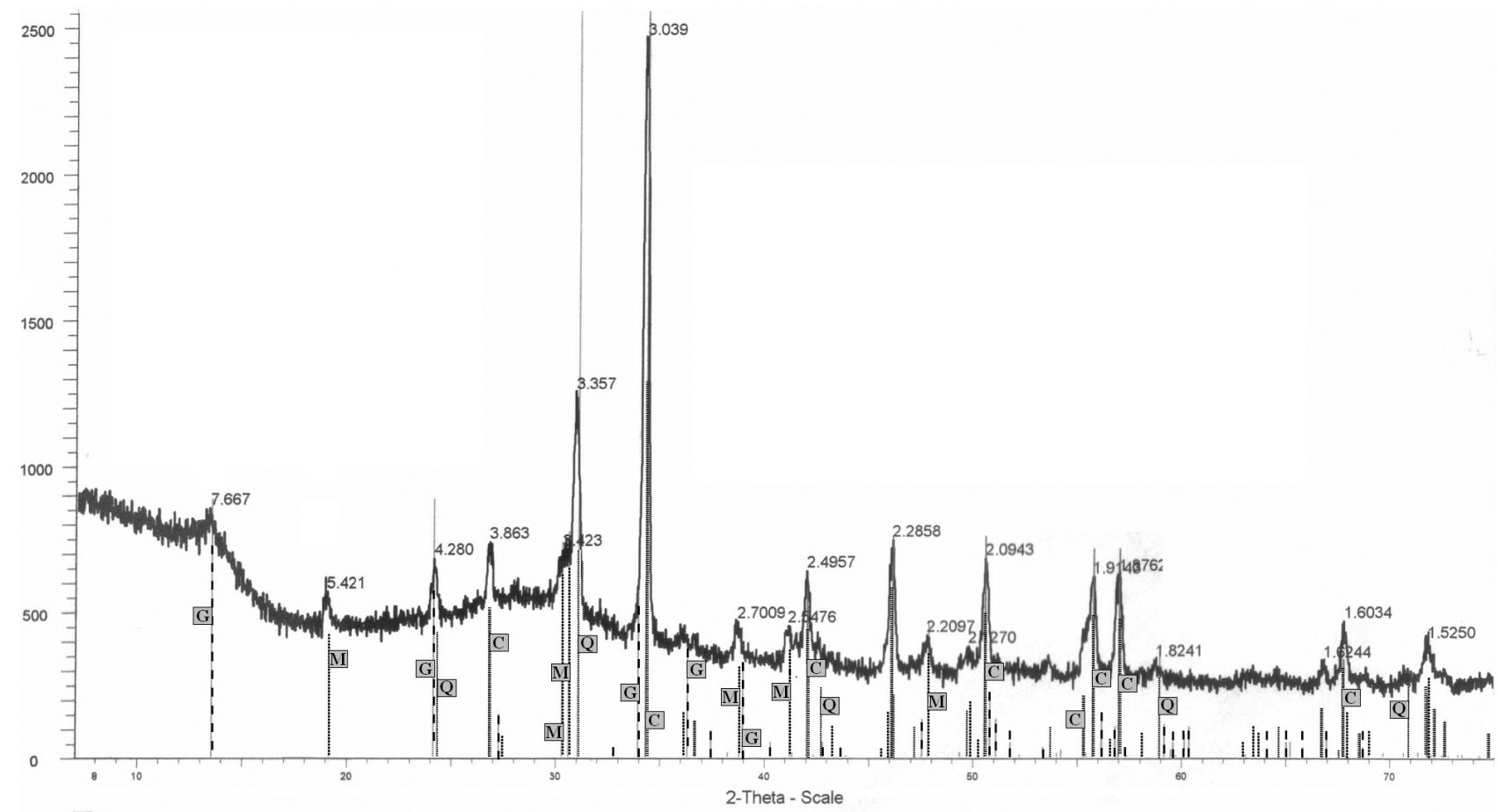

Wpopiol? - File: CA07002asol.RAW - Type: 2 Th/Th locked - Start: $7.000^{\circ}$ - End: $75.000^{\circ}$ - Step: $0.020^{\circ}$ - Step time: 1.0 s - Temp: $27.0^{\circ} \mathrm{C}$ - Time Started: 3 s - 2-Theta: $7.000^{\circ}$ - Theta: $3.500^{\circ}$ - - Phi: 0.1

QUARTZ Q] [i, 46-1045 (") - Quartz, syn - Y: $50.00 \%$ - SiO2 - d x by: 1.000 - WL: 1.78897

CALCITE C [i] 05-0586 (") - Calcite, syn - Y: $79.17 \%$ - CaCO3 - $d x$ by: 1.000 - WL: 1.78897

GYPSUM G T.133-0311(") - Gypsum, syn - Y: $16.67 \%$ - CaSO4.2H2O - d x by: 1.000 - WL: 1.78897

MULLITE $\mathbb{M}$ [15-0776 (I) - Mullite, syn - Y: $14.58 \%$ - Al6Si2O13 - $\mathrm{d}$ x by: 1.000 - WL: 1.78897

Fig. 3. Results of XRD analysis of coal ash in this study. 
Table 1. Results of exhalation study

\begin{tabular}{cccc}
\hline $\begin{array}{c}\text { Ash layer thickness } \\
(\mathrm{m})\end{array}$ & $\begin{array}{c}\text { Total }^{226} \mathrm{Ra} \text { in ash } \\
(\mathrm{Bq})\end{array}$ & $\begin{array}{c}\text { Total Rn in air inside can } \\
(\mathrm{Bq})\end{array}$ & $\begin{array}{c}\text { Exhalation coefficient } \\
(\%)\end{array}$ \\
\hline 0.010 & 10.7 & 1.6 & 15.0 \\
0.026 & 26.8 & 2.7 & 10.0 \\
0.050 & 51.3 & 2.4 & 4.7 \\
0.065 & 65.7 & 2.8 & 4.2 \\
0.084 & 85.6 & 2.8 & 3.3 \\
0.103 & 104.9 & 2.8 & 2.7 \\
0.127 & 128.8 & 2.4 & 1.9 \\
0.158 & 161.0 & 2.5 & 1.6 \\
\hline
\end{tabular}
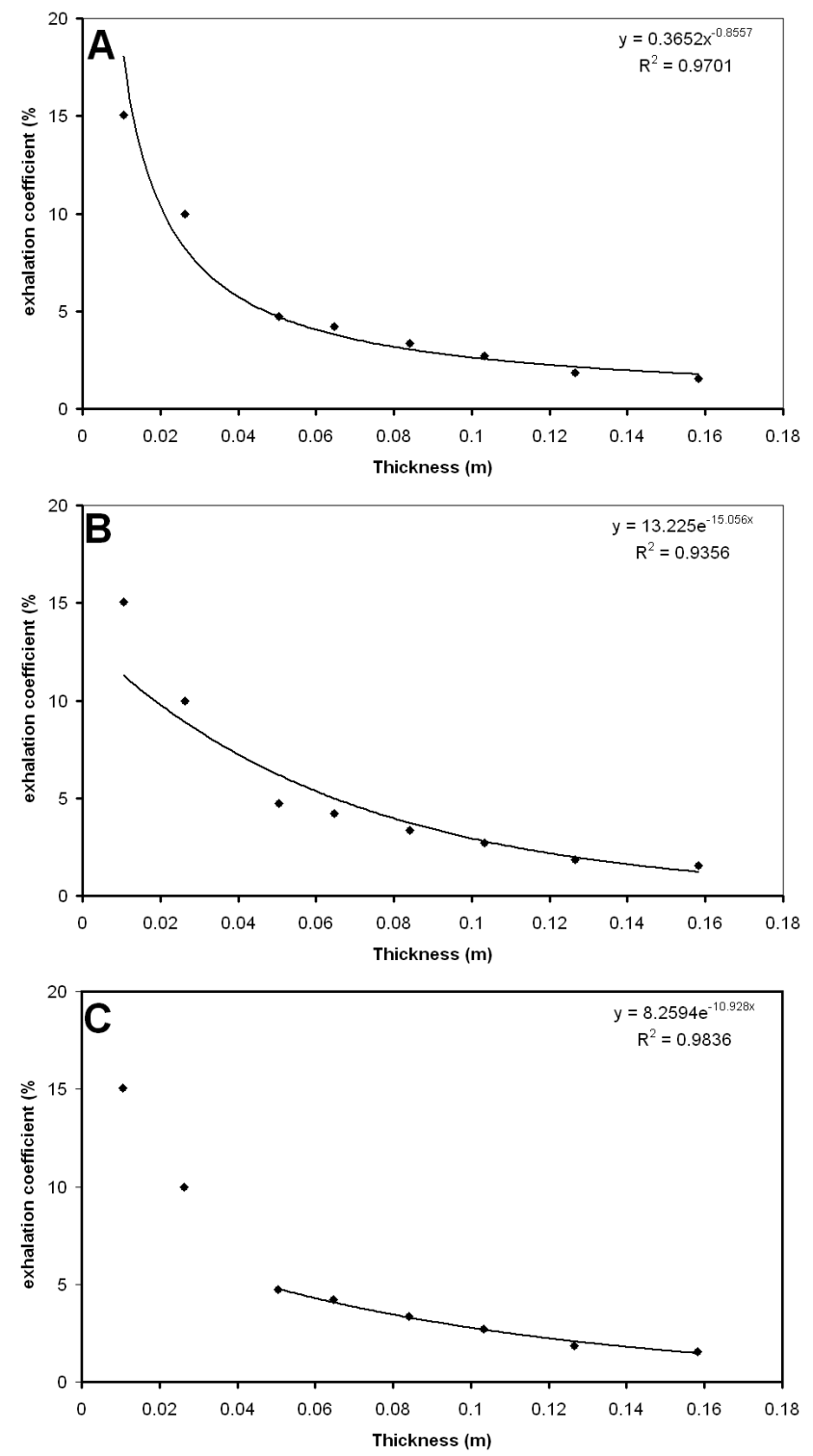

Fig. 4. Relation between layer thickness and exhalation coefficient: (A) Power trend calculated for all data; (B) Exponential trend calculated for all data; $(C)$ Exponential trend calculated for layers thicker than $0.05 \mathrm{~m}$.

\section{RESUltS AND CONCLUSIONS}

According to gamma spectrometric measurements (Fig. 2) uranium content of coal ash stored in the disposal varies in the range of 1.6 to $6.7 \mathrm{ppm}$, with mean value $4.5 \mathrm{ppm}\left(56 \mathrm{~Bq} \mathrm{~kg}^{-1}\right)$. Thorium content varies in the range 3.6-17.1 ppm with mean value $12.5 \mathrm{ppm}$ (51 $\mathrm{Bq} \mathrm{kg}^{-1}$ ).

Basic physical parameters of ash obtained in this study are: specific density, $1900 \mathrm{~kg} \mathrm{~m}^{-3}$; packing density, 740 $\mathrm{km} \mathrm{m}^{-3}$; porosity, $60 \%$; activity of ${ }^{226} \mathrm{Ra}, 56 \mathrm{~Bq} \mathrm{~kg}^{-1}$. Quartz, mullite, calcite and gypsum crystalline phases can be identified in the ash by means of XRD method (Fig. 3 ). Occurrence of gypsum and regenerated calcite is probably responsible for the rapid lithification of ashes observed in the field.

Results of exhalation study are presented in Table 1 . Total radium content of analyzed samples varied from 10 to $160 \mathrm{~Bq}$, depending on the sample size. Total amount of radon in air inside can varied from 1.6 to $2.5 \mathrm{~Bq}$ and exhalation coefficient varied from 1.6 to $15 \%$.

Relation between ash layer thickness and exhalation coefficient is shown in Fig. 4, where attempts to fit various trends have been performed. The best fit for all gathered data with $\left(R^{2}=0.97\right)$ has been obtained for the power trend (Fig. 4A). Good fit of obtained results to the power function $y=3652 x^{-0.8557}$ is quite reasonable taking into account the fact that surface/volume ratio of the sample is decreasing for increasing sample thickness according to formula $y=x^{-1}$. However, this kind of function reaches infinity for zero thickness value. It would require that exhalation coefficient for thinner layer approaches infinity.

Taking into account the fact, that the maximum value of exhalation coefficient cannot be higher than 100\%, other trend functions available in Excel@ has been applied. The best fit with highest $R^{2}$ value (0.9356) has been obtained for exponential function $y=13.225 e^{-15.056 x}$ (Fig. $4 \mathrm{~B})$. In this case exhalation coefficient for the layer of zero thickness is $13.225 \%$, which is quite reasonable result. For layer of $0.001 \mathrm{~m}$ thick, the obtained result is 
13.03. Slightly better fit $\left(R^{2}=0.9836\right)$ was obtained if only samples thicker than $0.05 \mathrm{~m}$ were taken into account (Fig. 4C). In such a case exhalation coefficient for zero thickness layer is 8.2594 , and for layer of $0.001 \mathrm{~m}$ thick is 8.17 .

Considering the emanation coefficient is the fraction of $\mathrm{Rn}$ atoms which are able to escape the solid phase of the sample and enter air in open pores, the exhalation coefficient for layer's thickness corresponding to grain size may be regarded as approximation of the emanation coefficient. Exhalation of radon from the sample inside the can should be analyzed as three component processes: (1) emanation from mineral grains; (2) diffusion inside the ash and exhalation from the ash layer; (3) diffusion in the air inside the can. In the case of ${ }^{222} \mathrm{Rn}$ with its half life time 3.8 day, diffusion gradient for 10-20 centimeters in air of $20^{\circ} \mathrm{C}$ can be neglected for taking into account its air diffusion rate (Cothern and Smith, 1987). So, the main components of the process are process- 1 and -2 .

The second process, diffusion inside the ash layer becomes more significant when the sample is thick. For extremely thin layer comparable with grain size only the emanation from single mineral grains exits. So, thinner the layer the more important is emanation component of the process of exhalation.

Increasing layer thickness more than $0.026 \mathrm{~m}$ does not significantly result in the value of exhaled radon (Table 1). The coal ash is relatively fine grained material, the radon "born" in deeper horizons of the layer cannot reach the sample surface. Obtained results indicate that measurements of exhalation for various layer thicknesses are necessary to obtain the equation which enables to estimate the emanation coefficient.

Process of radon release from fine grained coal ash material, without internal ventilation resulting from convection or atmospheric pressure, is restricted to thin external layer, no more than few centimeters thick. Such thin layers can release amount of radon comparable with huge tailings of analogous material.

Acknowledgments-Research was sponsored by grant 20022/ W/ING/07-36.

\section{REFERENCES}

Al-Jarallaha, M. I., Abu-Jaradb, F. and Fazal-ur-Rehmana (2001) Determination of radon exhalation rates from tiles using active and passive techniques. Radiat. Meas. 34, 491495.

Azam, A., Naqvi, A. H. and Srivastava, D. S. (1995) Radium concentration and radon exhalation measurements using LR115 type II plastic track detector. Nucl. Geophys. 9(6), 653657.

Baixeras, C., Erlandsson, B., Fonta, Ll. and Jönsson, G. (2001) Radon emanation from soil samples. Radiat. Meas. 34, 441-
443.

Bareja, E., Saldan, M. and Strzelecki, R. (1987) Rudy uranu i toru. Budowa geologiczna Polski T.VI Zloża Surowców mineralnych (Osika, R., ed.), 213-228, Wydawnictwa Geologiczne Warszawa (in Polish).

Chauhan, R. P. and Chakarvarti, S. K. (2002) Radon diffusion through soil and fly ash: effect of compaction. Radiat. Meas. 35, 143-146.

Chyi, L. L., Quick, T. J., Yang, F. T. and Chen, C. H. (2005) Soil gas radon spectra and earthquakes. Terr. Atmos. Ocean. Sci. 16, 763-774.

Chyi, L. L., Quick, T. J., Yang, T. F. and Chen, C-H. (2010) The experimental investigation of soil gas radon migration mechanisms and its implication in earthquake forecast. Geofluids 10, 556-563.

Chyi, L. L., Quick, T. J., Yang, T. F. and Chen, C. H. (2011) The origin and detection of spike-like anomalies in soil gas radon time series. Geochem. $J . \mathbf{4 5}$, this issue, 431-438.

Cothern, R. C. and Smith, J. E., Jr. (1987) Environmental Radon. Plenum Press, New York, 335 pp.

Durrance, E. M. (1986) Radioactivity in Geology. Principles and Applications, Ellis Horwood Ltd., Chichester, 437 pp.

Fazal-ur-Rehmana, Al-Jarallaha, M. I., Musazaya, M. S. and Abu-Jaradb, F. (2003) Application of the can technique and radon gas analyzer for radon exhalation measurements. Appl. Radiat. Isotopes 59, 353-358.

Fu, C. C., Yang, T. F., Du, J., Walia, V., Chen, Y. G., Liu, T. K. and Chen, C-H. (2008) Variations of helium and radon concentrations in soil gases from an active fault zone in southern Taiwan. Radiat. Meas. 43, S348-S352.

Fu, C. C., Yang, T. F., Walia, V., Liu, T. K., Lin, S. J., Chen, CH. and Hou, C. S. (2009) Variations of soil-gas composition around the active Chihshang Fault in a plate suture zone, eastern Taiwan. Radiat. Meas. 44, 940-944.

IAEA (1992) Measurements and Calculation of Radon Releases from Uranium Mill Tailings, International Atomic Energy Agency. Technical reports series, No. 333, Vienna.

Jönson, G. (1999) Experience from using plastic film in radon measurement. Radiat. Meas. 31, 265-270.

Kies, A., Nawrot, A., Tosheva, Z. and Jania, J. (2011) Natural radioactive isotopes in glacier meltwater studies. Geochem. $J .45$, this issue, 423-429.

Kumar, R., Mahur, A. K., Sengupta, D. and Prasad, R. (2005) Radon activity and exhalation rates measurements in fly ash from a thermal power plant. Radiat. Meas. 40, 638-641.

Mahur, A. K., Kumar, R., Mishra, M., Sengupta, D. and Prasad, R. (2008) An investigation of radon exhalation rate and estimation of radiation doses in coal and fly ash samples. Appl. Radiat. Isotopes 66, 401-406.

Mehra, R., Singh, S. and Singh, K. (2011) Assessment of the average effective dose from the analysis of ${ }^{226} \mathrm{Ra},{ }^{232} \mathrm{Th}$ and ${ }^{40} \mathrm{~K}$ in soil samples from Punjab, India. Geochem. J. 45, this issue, 497-503.

Oufni, L. (2003) Determination of the radon diffusion coefficient and radon exhalation rate Moroccan quaternary samples using the SSNTD technique. J. Radioanalyt. Nucl. Chem. 256(3), 581-586.

Sharma, D. K., Kumar, A., Kumar, M. and Singh, S. (2003) Study of uranium, radium and radon exhalation rate in soil 
samples from some areas of Kangra district, Himachal Pradesh, India using solid-state nuclear track detectors. Radiat. Meas. 36, 363-366.

Singh, A. K., Sengupta, D. and Prasad, R. (1999) Radon exhalation rate and uranium estimation in rock samples from Bihar uranium and copper mines using the SSNTD technique. Appl. Radiat. Isotopes 51, 107-113.

Solecki, A. T. (1999) Radon emanation of selected Sudetic rocks. ICGG-5th, Debrecen, Hungary, Aug. 30-Sept. 3, 1999.

Tchorz-Trzeciakiewicz, D. E. and Solecki, A. T. (2011) Seasonal variation of radon concentrations in atmospheric air in the Nowa Ruda area (Sudety Mountains) of southwest Poland. Geochem. J. 45, this issue, 455-461.

Tufail, M., Sikander, M. M., Arif, M., Quereshi, A. A., Yasir, A. and Khan, H. A. (2000) Application of a closed-can technique for measuring radon exhalation from mine samples of Punjab, Pakistan. J. Environ. Radioact. 50, 267-275.

Vaupotič, J., Ogrinc, N., Brenčič, M. and Kobal, I. (2011) Tritium mapping in spring waters in Slovenia. Geochem. $J$. 45, this issue, 505-512.

Walia, V., Mahajan, S., Kumar, A., Singh, S., Bajwa, B. S., Dhar, S. and Yang, T. F. (2008) Fault delineation study using soil- gas method in the Dharamsala area, NW Himalayas, India. Radiat. Meas. 43, S337-S342.

Walia, V., Yang, T. F., Hong, W. L., Lin, S. J., Fu, C. C., Wen, K. L. and Chen, C-H. (2009) Geochemical variation of soilgas composition for fault trace and earthquake precursory studies along the Hsincheng Fault in NW Taiwan. Appl. Radiat. Isotopes 67, 1855-1863.

Wysocka, M. (2011) Radon in Jurassic caves of the KrakowCzestochowa Upland. Geochem. J. 45, this issue, 447-453. Yang, T. F., Chou, C. Y., Chen, C-H., Chyi, L. L. and Jiang, J. H. (2003) Exhalation of radon and its carrier gases in SW Taiwan. Radiat. Meas. 36, 425-429.

Yang, T. F., Walia, V., Chyi, L. L., Fu, C. C., Wang, C. C., Chen, C-H., Liu, T. K., Song, S. R., Lee, C. Y. and Lee, M. (2005) Variations of soil radon and thoron concentrations in a fault zone and prospective earthquakes in SW Taiwan. Radiat. Meas. 40, 496-502.

Yang, T. F., Wen, H. Y., Fu, C. C., Lee, H. F., Lan, T. F., Chen, A. T., Hong, W. L., Lin, S. J. and Walia, V. (2011) Soil radon flux and concentrations in hydrothermal area of the Tatun Volcano Group, Northern Taiwan. Geochem. J. 45, this issue, 483-490. 